\title{
Asbestosis as a precursor of asbestos related lung cancer: results of a prospective mortality study
}

\author{
Janet $M$ Hughes, Hans Weill
}

\begin{abstract}
A prospective mortality study of 839 men employed in the manufacture of asbestos cement products in 1969 examined lung cancer risk in relation to lung fibrosis seen on chest $x$ ray film, controlling for age, smoking, and exposure to asbestos. Twenty or more years after hire, no excess of lung cancer was found among workers without radiographically detectable lung fibrosis, even among long term workers ( $\geq 21.5$ years); nor was there a trend in risk by level of cumulative exposure to asbestos among such workers. By contrast, employees with small opacities ( $\geq 1 / 0$; ILO classification) experienced a significantly raised risk of lung cancer (nine observed deaths $v 2 \cdot 1$ expected), even though their exposures to asbestos were similar to the exposures of long term workers without opacities. In this population, excess risk of lung cancer was restricted to workers with $x$ ray film evidence of asbestosis, a finding consistent with the view that asbestos is a lung carcinogen because of its fibrogenicity.
\end{abstract}

Epidemiological studies of asbestos workers have shown a dose relation with both asbestosis and risk of lung cancer (see, for example, references ${ }^{1-3}$ ), but few have considered the possible role of asbestosis itself in risk of lung cancer. It has been repeatedly documented that persons with asbestosis are at excess risk of developing lung cancer. ${ }^{4-7}$ What has been uncertain is whether this risk is directly related to the exposure to asbestos or to the lung fibrosis.

This issue is considered in a prospective mortality study which includes information on four possible determinants of lung cancer risk-namely, age, cigarette smoking, exposure to asbestos, and radiographic evidence of asbestosis. As in any study of asbestos workers, mesothelioma risk is assessed.

Tulane University School of Medicine, and School of Public Health and Tropical Medicine, New Orleans, Louisiana, USA

$\mathrm{J} M$ Hughes, $\mathrm{H}$ Weill
We are unaware, however, of a hypothesis that lung fibrosis may be causally related to the development of mesothelioma, and such a potential relation is not the focus of this study.

\section{Population and methods}

The study population consisted of all workers in two New Orleans asbestos cement manufacturing plants in 1969. Over a period of about one year, an interview and pulmonary function tests were administered and chest $x$ ray films taken. Lung function and $x$ ray film results in relation to exposure to asbestos have been reported previously. ${ }^{8}$

Information concerning the types of asbestos used in these plants and air sampling data have been described elsewhere'; job histories in conjunction with hygiene data were used to estimate cumulative exposures for individual subjects.

Chest $x$ ray films were obtained for 908 workers, of which 68 were excluded from analyses: 32 retirees (a possible survivor population) and 36 women, leaving a total cohort of 840 men (roughly $88 \%$ of the 1969 employees).

Chest $x$ ray films were classified independently in 1970-1 by three experienced readers (Benjamin Felson, John C Gilson, and Morton $M$ Ziskind) using the International Labour Office (ILO) U/C international classification of radiographs of the pneumoconioses (1971), and without knowledge of the person's history of exposure. Of the $840 x$ ray films, one was judged, by the criteria of two or more readers, to be unreadable; the person was excluded from all results. By median reading for quality, of the remaining 839 , eight $(1 \%)$ were category 3 (poor); $638(76 \%)$ were category 1 (optimal).

Follow up (through 1983) was performed as part of a mortality study of all persons ever employed in these plants; these results have been reported previously. ${ }^{9}$ For the 839 who are the subject of this report, 838 were successfully traced; of these, 154 had died. Death certificates, obtained for 153, were coded using the 8 th revision of the International Classification of Diseases (the two workers either not traced or without a death certificate were aged 32 and 35 in 1969, respectively, so are unlikely to have died of lung cancer).

In the standardised mortality ratio (SMR) 
analyses, cause specific mortality was compared with that expected based on Louisiana rates. In these analyses, only mortality experience at least six months after the chest $x$ ray film and 20 years from hire was considered, thus allowing sufficient latency time for any exposure induced cancers. During 19709, age adjusted death rates for lung cancer for the two parishes (counties) in which the plants were located were $25 \%$ and $12 \%$ higher than the overall State rate for white and non-white men respectively. The calculated SMRs are therefore likely to be somewhat inflated due to use of Louisiana rates, but parish rates were judged too unstable for use.

In comparing two SMRs, the likelihood ratio test based on the Poisson distribution was used. ${ }^{10}$

To quantitatively assess the role of smoking and other factors on the risk of lung cancer, survival analyses, based on the Cox proportional hazards model, was performed (using BMDP procedure $2 \mathrm{~L}$ ). The same workers as in the SMR analyses were included (those at least 20 years after hire during follow up), and the study period was the same (each worker entering analysis at six months after radiography or 20 years after hire, whichever was later, and follow up ending at death or at the end of 1983).

\section{Results}

The age and smoking distributions of workers in the two plants were similar in 1969 . Overall, the mean age was $45 \cdot 1$ (range 21-68), with a mean duration of employment of $17 \cdot 1$ years. For cigarette smoking, $25 \%$ were ex-smokers and $52 \%$ current smokers, a prevalence similar to the $55 \%$ reported for male United States blue collar workers aged 20-64 in $1970 .^{11}$

Using the median reading, each film was classified into one of several mutually exclusive, orderd $x$ ray categories; presence of large opacities (four films); small opacities without large opacities (79 films); pleural changes only (71); and no abnormalities (595). (In keeping with the 1971 classification, in which films were judged separately for irregular and rounded small opacities, films with small opacities were first classified on the basis of irregular or only rounded opacities, but subsequent mortality analyses found no relation between mortality and type of small opacity; type was therefore ignored.) As only four workers had large opacities, they were excluded from all further analyses (all died during the follow up period; the causes of death were ischaemic heart disease, asbestosis, lung cancer, and lung fibrosis).

Agreement of the $x$ ray film readers was good: for profusion of small opacities by the three readers respectively, $94 \%, 94 \%$, and $88 \%$ of the readings were within one subcategory of the median. Of the 79 films classified $\geq 1 / 0$ by median reading, the three readers classified $82 \%, 86 \%$, and $90 \%$ of these films as $\geq 1 / 0$.
Table 1 Prevalence of small opacities (median reading) by cumulative asbestos exposure category

\begin{tabular}{lllll}
\hline $\begin{array}{l}\text { Cumulative } \\
\text { exposure } \\
(\text { mppcf-y) }\end{array}$ & $\begin{array}{l}\text { Years } \\
\text { employed } \\
\text { (mean }(S D))\end{array}$ & $\begin{array}{l}\text { No in } \\
\text { group } \dagger\end{array}$ & \multicolumn{2}{l}{$\begin{array}{l}\text { Small opacities } \\
\text { (ILO class) }\end{array}$} \\
\hline$<25$ & $4 \cdot 4(3 \cdot 1)$ & 228 & $1 \cdot 3$ & 4.0 \\
$25-99$ & $19 \cdot 5(5 \cdot 2)$ & 240 & $7 \cdot 5$ & 14.0 \\
$100-149$ & $22.6(3.4)$ & 185 & 12.4 & 14.2 \\
$\geq 150$ & $24.3(4 \cdot 3)$ & 182 & 19.2 & 18.4 \\
Total & $17 \cdot 1(9 \cdot 0)$ & 835 & 9.5 & 11.9 \\
\hline
\end{tabular}

$\star$ Millions of particles per cubic foot of air $\times$ years.

$\dagger$ Four with large opacities excluded.

Table 2 Observed $(O)$ and expected $(E)$ deaths 20 or more years from hire during June 1970-December 1983 ( $n=646$, 4897 person-years)

\begin{tabular}{lcc}
\hline Cause (ICD 8th rev) & O/E & $\begin{array}{l}S M R \\
(100 \times O / E)\end{array}$ \\
\hline All causes & $134 / 163 \cdot 5$ & $82 \cdot 0$ \\
All malignancies (140-209): & $52 / 39 \cdot 0$ & $133 \cdot 5 \star$ \\
Respiratory (162-3) & $26 / 15 \cdot 4$ & $169 \cdot 0 \star \star$ \\
Mesothelioma & 8 & - \\
Larynx (161) & $0 / 0 \cdot 6$ & 0 \\
Buccal/pharynx (140-9) & $0 / 1 \cdot 5$ & 0 \\
Digestive (150-9) & $6 / 9 \cdot 2$ & $65 \cdot 0$ \\
Bladder, kidney (188-9) & $2 / 1 \cdot 4$ & $143 \cdot 2$ \\
Lymphatic (200-9) & $1 / 2 \cdot 5$ & $39 \cdot 6$ \\
Miscellaneous $\dagger$ & $7 / 4 \cdot 3 \ddagger$ & $164 \cdot 0$ \\
Residual & $2 / 4 \cdot 1$ & $48 \cdot 8$ \\
Cardiovascular (390-448) & $44 / 81 \cdot 1$ & $54 \cdot 3$ \\
Non-malignant respiratory diseases & $1 / 5 \cdot 7$ & $17 \cdot 5$ \\
(470-4, 480-6, 490-3) & 6 & - \\
Pneumoconiosis (515) & $7 / 12 \cdot 5$ & $55 \cdot 9$ \\
External causes (800-998) & $24 / 25 \cdot 2$ & $95 \cdot 2$ \\
Residual &
\end{tabular}

$\star \star \star$ Significantly elevated, Poisson one tailed test; $p=0.02\left({ }^{\star}\right)$; $\mathrm{p}<0.01(\star \star)$.

tSee text for definition.

ISeven cases observed includes two liver cancers; if primary the code would be 155 bringing the observed digestive cancers closer to expected.

Primarily to assess the validation of the $x$ ray readings, factors related to presence of small opacities were investigated. By multiple logistic regression, the presence of small opacities profusion $\geq 1 / 0$ was found to be significantly related to age, cigarette smoking (either pack-years or ever smoking), cumulative asbestos exposure, and plant, with a higher prevalence in plant 2 (all $\mathrm{p}$ values $<0.001$ after accounting for the other factors). By smoking group $10 \cdot 2 \%$ of current and ex-smokers (66 of 645 ), and $6.5 \%$ (13 of 190) of never smokers had small opacities $\geq 1 / 0$. By plant the percentages were $5.4 \%$ and $11.9 \%$. Table 1 shows the prevalences of small opacities by cumulative asbestos category.

With the exception of plant, the same variables (age, smoking, and cumulative asbestos exposure) were significantly related to presence of opacities $0 / 1$ 
( $p<0.01$ for each variable after accounting for the others).

\section{MORTALITY}

Of the 154 deaths occurring during follow up, 29 were from lung cancer (all cigarette smokers), six from asbestosis, and eight from mesothelioma.

Of the total $839 x$ ray film participants in 1969,646 were hired in 1963 or earlier, thus achieving at least 20 years of follow up by the end of 1983. These workers were, on average, 48.9 years old in 1969 and had been employed for 21.3 years.

Twenty or more years after hire, the SMR for all causes combined was not raised (table 2). Mortality due to cancer, however, was significantly raised ( 52 observed deaths $v 39.0$ expected; $\mathrm{p}=0.02$ ), as was respiratory cancer $(26 v 15.4 ; \mathrm{p}<0.01)$. The category of miscellaneous cancers, which included secondary respiratory or digestive cancers, and cancers with no specification of site, was also raised (7 $v$ $4 \cdot 3)$, though not significantly $(p=0 \cdot 14)$. Of the seven cases in this category, two were liver cancer, with no designation as to whether this was primary or secondary; if primary, they would have accounted for some of the existing deficit of digestive cancers $(6 v$ 9.2).

All of the excess cancer, including respiratory cancer, occurred in the second plant, that with the higher prevalence of small opacities. This difference in risk is consistent with that reported previously ${ }^{9}$ for the larger cohort of all workers ever employed in these plants (and followed up through 1981). Mortality in relation to $x$ ray film category was, however, reasonably consistent for the two plants and potential plant factors were taken into account in all analyses. Therefore, all further results are reported for the two plants combined.

In the larger cohort, risk for cancer was found to be related to cumulative asbestos exposure. ${ }^{9}$ In the subset which is the subject of this report, lung cancer risk was not significantly associated with duration of employment or cumulative exposure. This may be due to a restricted range for these variables-for example, in $1969,72 \%$ had worked in the plant for 18 to 25 years.

\section{MORTALITY IN RELATION TO $X$ RAY CATEGORY}

Table 3 gives a description of workers with at least 20 years of follow up, classified by $x$ ray film category. Those without abnormalities on $x$ ray film have been divided into two groups by the median duration of employment.

Those without abnormalities but employed at least 21.5 years are reasonably comparable with those with small opacities, although there are differences as would be expected from the previously stated deter-

Table 3 Description of workers ${ }^{\star}$ with follow up $\geq 20$ years by category of $x$ ray film abnormality in 1969 (median reading)

\begin{tabular}{|c|c|c|c|c|c|}
\hline & \multicolumn{2}{|c|}{ No abnormalities } & \multirow[b]{2}{*}{$\begin{array}{l}\text { Pleural } \\
\text { only }\end{array}$} & \multicolumn{2}{|c|}{ Small opacities (ILO class) } \\
\hline & $\begin{array}{l}\text { Employed } \\
\leq 21.5 y\end{array}$ & $\begin{array}{l}\text { Employed } \\
>21.5 y\end{array}$ & & $0 / 1$ & $\geq 1 / 0$ \\
\hline $\begin{array}{l}\text { No } \\
\text { Age (y) } \\
\text { \% Ever smokers } \\
\text { Years employed } \\
\text { Exposure concentration (mppcf) } \\
\text { Cumulative exposure (mppcf-y) } \\
\text { Years of follow up }\end{array}$ & $\begin{array}{l}209 \\
45 \cdot 0(8 \cdot 4) \\
77 \\
16 \cdot 6(5 \cdot 1) \\
4 \cdot 7(2 \cdot 8) \\
83(60) \\
31 \cdot 1(5 \cdot 0)\end{array}$ & $\begin{array}{l}211 \\
50 \cdot 5(6 \cdot 7) \\
73 \\
24 \cdot 3(3 \cdot 6) \\
6 \cdot 2(3 \cdot 4) \\
151(88) \\
37 \cdot 7(4 \cdot 9)\end{array}$ & $\begin{array}{l}62 \\
48 \cdot 9(6 \cdot 5) \\
69 \\
21 \cdot 6(4 \cdot 0) \\
5 \cdot 2(2 \cdot 5) \\
114(54) \\
35 \cdot 0(4 \cdot 6)\end{array}$ & $\begin{array}{l}83 \\
51 \cdot 1(7 \cdot 4) \\
84 \\
23 \cdot 1(5 \cdot 4) \\
6 \cdot 7(5 \cdot 8) \\
162(162) \\
36 \cdot 0(5 \cdot 8)\end{array}$ & $\begin{array}{l}77 \\
52 \cdot 7(6 \cdot 4) \\
83 \\
23 \cdot 4(4 \cdot 4) \\
7 \cdot 5(5 \cdot 2) \\
177(126) \\
35 \cdot 5(5 \cdot 6)\end{array}$ \\
\hline
\end{tabular}

${ }^{\star}$ Means (SD) unless otherwise noted.

Table 4 Mortality from selected causes $\geq 20$ years after hire; by category of $x$ ray film abnormality in 1969

\begin{tabular}{|c|c|c|c|c|c|}
\hline & \multicolumn{2}{|l|}{ No abnormalities } & \multirow[b]{2}{*}{$\begin{array}{l}\text { Pleural only }(n=62) \\
O / E(S M R)\end{array}$} & \multicolumn{2}{|c|}{ Small opacities (ILO class) } \\
\hline & $\begin{array}{l}\text { Employed } \leq 21.5 y \\
O / E(S M R)\end{array}$ & $\begin{array}{l}\text { Employed }>21.5 y \\
O / E(S M R)\end{array}$ & & $\begin{array}{l}0 / 1(n=83) \\
O / E(S M R)\end{array}$ & $\begin{array}{l}\geq 1 / 0(n=77) \\
O / E(S M R)\end{array}$ \\
\hline $\begin{array}{l}\text { All causes } \\
\text { All cancers } \\
\text { Respiratory cancer } \\
\text { Mesotheliomat }\end{array}$ & $\begin{array}{l}26 / 39 \cdot 9(65 \cdot 2) \\
10 / 9 \cdot 3(107 \cdot 7) \\
4 / 3 \cdot 7(109 \cdot 3) \\
2\end{array}$ & $\begin{array}{l}35 / 61 \cdot 0(57 \cdot 4) \\
12 / 14 \cdot 7(81 \cdot 8) \\
6 / 5 \cdot 8(103 \cdot 0) \\
3\end{array}$ & $\begin{array}{l}12 / 15 \cdot 9(75 \cdot 3) \\
5 / 3.8(129 \cdot 9) \\
2 / 1.5(133 \cdot 0) \\
1\end{array}$ & $\begin{array}{l}27 / 23 \cdot 7(113 \cdot 8) \\
12 / 5 \cdot 7(211 \cdot 1) \\
4 / 2 \cdot 3(177 \cdot 5) \\
2\end{array}$ & $\begin{array}{l}30 / 22 \cdot 3(134 \cdot 8) \\
12 / 5 \cdot 3(225 \cdot 6)^{\star} \dagger \\
9 / 2 \cdot 1(432 \cdot 5)^{\star \star} \dagger \\
0\end{array}$ \\
\hline
\end{tabular}

$\star \star \star$ Significantly raised, Poisson distribution; $p<0.02(\star) ; p<0.01(\star \star)$.

†Significantly different from corresponding risk in those without abnormalities; employed $\geq 21.5$ years; likelihood ratio test.

†Another mesothelioma death occurred after the end of follow up. 
Table 5 Lung cancer deaths $\geq 20$ years after hire: workers without chest $x$ ray film abnormalities in 1969, by cumulative exposure quintiles

\begin{tabular}{lrlrr}
\hline $\begin{array}{l}\text { Cumulative } \\
\text { exposure } \\
\text { (mppcf-y) }\end{array}$ & No & $\begin{array}{l}\text { Years } \\
\text { worked } \\
\text { (mean }(S D))\end{array}$ & $O / E$ & \multicolumn{1}{l}{$\begin{array}{l}S M R \\
(100 \times O / E)\end{array}$} \\
\hline$<51$ & 83 & $13 \cdot 5(6 \cdot 4)$ & $2 / 1 \cdot 1$ & $189 \cdot 0$ \\
$\geq 51<86$ & 86 & $20 \cdot 5(4 \cdot 3)$ & $1 / 1 \cdot 9$ & $53 \cdot 7$ \\
$\geq 86<122$ & 84 & $21 \cdot 2(3 \cdot 7)$ & $1 / 2 \cdot 2$ & $46 \cdot 1$ \\
$\geq 122<170$ & 83 & $22 \cdot 6(3 \cdot 2)$ & $2 / 2 \cdot 2$ & $90 \cdot 2$ \\
$\geq 170$ & 84 & $24 \cdot 3(4 \cdot 5)$ & $4 / 2 \cdot 2$ & $183 \cdot 5$ \\
Total & 420 & $20 \cdot 5(5 \cdot 8)$ & $10 / 9 \cdot 5$ & $105 \cdot 5$ \\
\hline
\end{tabular}

minants of small opacities. One difference is in prevalence of cigarette smoking $(73 \% v 83 \%)$.

Among workers with no $x$ ray film abnormalities in 1969 , the lung cancer risk was not raised (five mesotheliomas, however, were found). For the long term workers in this group, there were six lung cancers compared with 5.8 expected (table 4). By contrast, among those with small opacities, profusion $\geq 1 / 0$, there were around seven excess malignancies, all of them due to lung cancer; the lung cancer risk was significantly raised $(9 v 2.1 ; \mathrm{p}<0.001)$ and significantly different from the risk in long term workers without abnormalities $(p<0.01$, likelihood ratio test).

A small excess of lung cancer was found among those with small opacities $0 / 1(4 v 2 \cdot 3)$ (as well as two mesotheliomas), but this was not a significant increase, nor was it significantly different from that of workers without abnormalities.

LUNG CANCER AMONG WORKERS WITH NEGATIVE FILMS When lung cancer risk among the 420 workers without abnormalities was examined by quintile of cumulative exposure to asbestos, no consistent trend was seen, with the highest SMRs occurring among those in the lowest and highest quintiles (table 5). The 83 workers in the lowest category had worked in the plants for a median of 12.9 years, so the somewhat raised risk for this group is likely to be a chance occurrence, rather than the occasionally observed phenomenon of increased risk among short term workers.

\section{SURVIVAL ANALYSIS}

Survival analysis was used to determine how much of the substantial difference in risk for lung cancer between workers with small opacities $(\geq 1 / 0)$ and those without such abnormalities on $x$ ray film can be explained by the differences in age, smoking, and exposure. In this analysis, those with small opacities $\geq 1 / 0$ were compared with all others combined.

When all 642 workers were included in the analysis, the most statistically significant factors for death due to lung cancer were pack-years of smoking and age ( $p<0.01$ for each, after accounting for the other). After accounting for pack-years, age, and exposure to asbestos (both cumulative and average

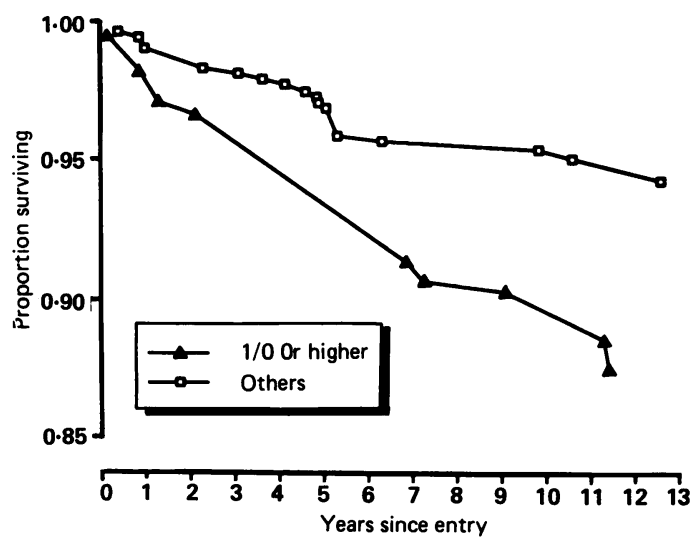

Adjusted lung cancer survival curves for workers with small opacities (profusion $\geq 1 / 0$ ) and all others combined, for current and ex-smokers only.

concentration, although neither was statistically significant), $x$ ray category was significant (one tailed $\mathrm{p}=0.04$ ). If only ever smokers are included, similar results are obtained ( $\mathrm{p}=0.03$ for $x$ ray category). Among ever smokers, the adjusted relative risk for lung cancer for those with small opacities $\geq 1 / 0$, compared with the other groups combined, was 2.88 (whereas the ratio of the SMRs for the $\geq 1 / 0$ workers and for all others combined was 3.6).

To illustrate these results, the adjusted survival curves for ever smokers are shown in the figure; these show the probability of not dying of lung cancer by time since entering follow up for workers with and without small opacities $\geq 1 / 0$, adjusted for age and pack-years of smoking.

\section{Discussion}

In this study, asbestos workers without $x$ ray film evidence of lung fibrosis did not experience a raised lung cancer risk whereas in workers with small opacities $\geq 1 / 0$ it was substantially increased even though their exposures to asbestos were similar to the long term workers without opacities. These findings are consistent with lung fibrosis (asbestosis) having been a necessary precursor for asbestos induced lung cancer in this population. Workers entered and terminated follow up, on average, at 22 and 35 years after hire, respectively; $21 \%$ entered follow up more than 25 years after hire. The follow up interval therefore included the period after the start of exposure when much of the excess risk of lung cancer is likely to occur.

In any study assessing the role of asbestosis in the development of lung cancer, the exposure estimates are essential in determining if the presence of asbestosis is simply a surrogate for level of exposure. The validity of the exposure estimates in this study is supported by the fact that these estimates have previously been used to establish the dose relations between exposure and chest $x$ ray film abormalities, 
pulmonary function reduction, and risk of lung cancer ${ }^{89}$ Also, there is no reason to believe that they should systematically underestimate the exposures of those with positive $x$ ray films, or overestimate the exposures of those with negative films.

The findings of our study are consistent with other epidemiological and pathological data for man on the effects of exposure to asbestos. There was evidence a decade ago that an exposure dose which resulted in excess risk of lung cancer would also produce asbestosis, ${ }^{12}$ although this finding is also consistent with asbestosis and lung cancer being independent dose related diseases. A pathological study of lung cancer in insulators found that $82 \%$ had radiographic evidence of asbestosis, and $100 \%$ had histological evidence of fibrosis, ${ }^{13}$ whereas a study of London factory workers found $90 \%$ of cases to have histological evidence. ${ }^{14}$

Recently, a necropsy series of amphibole asbestos miners found that two thirds of the cases of lung cancer also had histological evidence of asbestosis, that lung cancer proportional mortality was raised only in those with asbestosis, and the severity of asbestosis was a significant factor after accounting for age, smoking, and duration of exposure. ${ }^{1516}$

On the other hand, in a study of Quebec miners and millers, ${ }^{17}$ the authors concluded that most, but not necessarily all, cases of asbestos attributable lung cancer would show opacities before death. Fibrosis could have become detectable, however, in some of the cases during the sometimes prolonged interval between $x$ ray film and death ( $>20$ years for $17 \%$ of cases).

By contrast with virtually all other known human carcinogens, asbestos has been defined as non-genotoxic, ${ }^{18}$ suggesting the need for a mediating influence to explain the observed lung cancer risk.

Other forms of lung fibrosis, whether idiopathic or associated with collagen vascular disorders ${ }^{19}$ have also been associated with an increased risk of lung cancer. Silicotic subjects have been shown to experience raised risk of lung cancer, even though investigations of silica exposed workers have failed to convincingly show an overall lung cancer risk. ${ }^{20}$

The current study is the latest in an emerging body of evidence supporting the view that asbestos is a lung carcinogen because of its ability to cause lung fibrosis. Nevertheless, further results in support of these findings are necessary before a firm conclusion concerning such a mechanism can be reached.

Such a mechanism for asbestos induced lung cancer would have important practical implications. Because detectable asbestosis is not likely to result from current occupational and general environmental asbestos exposures, the prevention of the effect of exposure on lung fibrosis is likely also to prevent the excess risk of lung cancer. Conversely, when asbestosis is detected in an exposed population, excess lung cancers can be expected. Finally, these data may provide further evidence to support the common practice of attributing lung cancer to exposure to asbestos only if asbestosis is also present; otherwise, these tumours are, in most cases, due to cigarette smoking.

Requests for reprints to: Dr Janet $M$ Hughes, Tulane University Medical Center, 1700 Perdido Street, New Orleans Louisiana 70112, USA.

1 Acheson ED, Gardner MJ. Asbestos: the control limit for asbestos. An update of the relevant sections of the ill effects of asbestos upon health. London: Health and Safety Commission. HMSO, 1983.

2 Doll R, Peto J. Asbestos-effects on health of exposure to asbestos. London: Health and Safety Commission. HMSO, 1985.

3 Liddell FDK, Hanley JA. Relations between asbestos exposure and lung cancer SMRs in occupational cohort studies. Br J Ind Med 1985;42:389-96.

4 Berry G. Mortality of workers certified by pneumoconiosis medical panels as having asbestosis. $\mathrm{Br} J$ Ind Med 1981; 38:130-7.

5 Finkelstein M, Kusiak R, Suranyi G. Mortality among workers receiving compensation for asbestosis in Ontario. Canadian Medical Association Journal 1981;125:259-62.

6 Cookson WO, Musk AW, Glancy JJ, et al. Compensation, radiographic changes, and survival in applicants for asbestosis compensation. $\mathrm{Br} J$ Ind $\mathrm{Med}$ 1985;42:461-8.

7 Coutts II, Gilson JC, Kerr IH, Parkes WR, Turner-Warwick M. Mortality in cases of asbestosis diagnosed by a pneumoconiosis medical panel. Thorax 1987;42:111-6.

8 Jones RN, Diem JE, Hughes JM, Hammad YY, Glindmeyer HW, Weill $H$. Progression of asbestos effects: a prospective longitudinal study of chest radiographs and lung function. $\mathrm{Br}$ $J$ Ind Med 1989;46:97-105.

9 Hughes JM, Weill H, Hammad YY. Mortality of workers employed in two asbestos cement manufacturing plants. $\mathrm{Br} J$ Ind Med 1987;44:161-74.

10 Berry $G$. The analysis of mortality by the subject-years method. Biometrics 1983;39:173-84.

11 US Department of Health and Human Services. $A$ report of the Surgeon General. The health consequences of smoking. Cancer and chronic lung disease in the workplace. Rockville, Maryland: US Public Health Service, 1985.

12 Weill H. Asbestos. A summing up. In: Wagner JC, ed. Biological effects of mineral fibres. Vol 2. Lyon: International Agency for Research on Cancer, 1980:867-73. (IARC publ No 30.)

13 Kipen HM, Lilis R, Suzuki Y, Valciukas JA, Selikoff IJ Pulmonary fibrosis in asbestos insulation workers with lung cancer: a radiological and histopathological evaluation. $\mathrm{Br} J$ Ind Med 1987;44:96-100.

14 Newhouse ML, Berry G, Wagner JC. Mortality of factory workers in east London, 1933-1980. Br J Ind Med 1985;42: 4-11.

15 Sluis-Cremer GK, Bezuidenhout BN. Relation between asbestosis and bronchial cancer in amphibole asbestos miners. $\mathrm{Br} J$ Ind Med 1989;46:537-40.

16 Sluis-Cremer GK Bezuidenhout BN. Response to letter to the Editor. Br J Ind Med 1990;47:215-6.

17 Liddell FDK, McDonald JC. Radiological findings as predictors of mortality in Quebec asbestos workers. Br J Ind Med 1980;37:257-67.

18 Daniel FB. In vitro assessment of asbestos genotoxicity. Environ Health Perspect 1983;53:163-7.

19 Turner-Warwick M, Lebowitz M, Burrows B, Johnson A. Cryptogenic fibrosing alveolitis and lung cancer. Thorax 1980;35:496-9.

20 International Agency for Research on Cancer. Monograph on the evaluation of the carcinogenic risk of chemicals in humans. Vol 142. Silica and some silicates. Lyon: IARC, 1987.

Accepted 29 October 1990 